\title{
古典籍からの情報発掘 一再生としての生命誌、ネットワークー Excavation from old books - Biohistory as regeneration, Network -
}

\author{
矢野 環 同志社大学文化情報学部 \\ Tamaki YAN0 Faculty of Culture and Information Science, Doshisha Univ.
}

一群の古典籍が含む情報を適切にデータ化することにより、その系統判別などを科学的に説明 することができる。必ずしも文字情報のみではなく、図像情報もまた数理的分析の対象となる。 ここでは、三十六歌仙絵、池坊専応口伝、茄子茶入の数理的取り扱いを紹介寸る。

If we get appropriate data from a group of old books, we can scientifically explain the systematics of it. For mathematical treatment, we use not only character based data, but also graphical data. Here we will explain the case of "Painted scroll of thirty six famous poets", "Ikenobo Sennoh's book on flower arrangement" and "Tea caddys of egg plant type"..

\section{1 歌仙絵の系譜}

\section{1 三十六歌仙絵}

三十六歌仙絵とは、歌聖柿本人麻呂、古今和 歌集編纂者の紀貫之などからなる三十六人の歌 人を左右に番え、一首づつの和歌を対して十八 番の歌合せとしたものである。それは、藤原公 任(966-1041)による「三十六人撰」に由来し、 寿永二年(1183)頃には「三十六歌仙」と称され たという。そして覚盛法師によって歌合の様式 が整えられたというが定かでない。その絵巻で 白眉とされる鎌倉期に作られた「佐竹本三十六 歌仙絵巻」は、大正八年に売り立てられた時あ まりに高額であったため、一人づつの三十六枚 に切られたこと（絵巻切断）で著名である。そ の他にも上ケ畳本 (一部残存)、北野神社社宝歌
仙絵など著名なものがある。

北野神社本は、後水尾天皇から曼殊院良恕法 親王への手紙に「然者今度北野清水谷歌仙之躰 を可謄申存候」と書かれたごとく、一つの典型 とされていた。良恕法親王自身もまた慶長八年 に禁裏の歌仙絵を写している。

この歌仙絵は歌人の姿を絵画として鑑賞する とともに、流麗な筆致の和歌もまた見るに值す るように書かれている。そして、歌人毎に選ば れた歌が、実は歌仙絵によって様々であること がわかる。柿本人麻呂でも、著名な「ほのぼの と明石の浦の朝霧に、島かくれ行く船をしぞ思 ふ」の歌以外に、「龍田川紅葉葉流る神なびの、 三室の山に時雨降るらし」、或いは「梅の花其と も見えず久方の、あまぎる雪のなべて降れれば」 
などが書かれている本がある。歌人によっては 七種類の歌を数えることもできる。

どの歌を採用するかは、色々な歌仙絵をみれ ば、一見かなり気儘な選択に見える。しかし、 何らかの基準となる絵を参照しているとすれば、 歌もまたある程度の基準があったのでは、と思 われる。そして、現存する諸本での歌の異動を 調べれば、どのような歌の組み合わせが典型で あり、どのように派生してきたかが解るのでは ないかと期待される。

\section{2 文化情報学部本『三十六歌仙帖』}

同志社大学文化情報学部には、折帖となった 『三十六歌仙帖』がある。狩野博幸教授（元京 都国立博物館)の判断により購入されたもので、 濃彩で美麗な絵の上に達筆で和歌が書かれてい る。但し、斎宮女御のみは外されている。

これがどのような系統に属するかを、和歌の 選択から見てみよう。

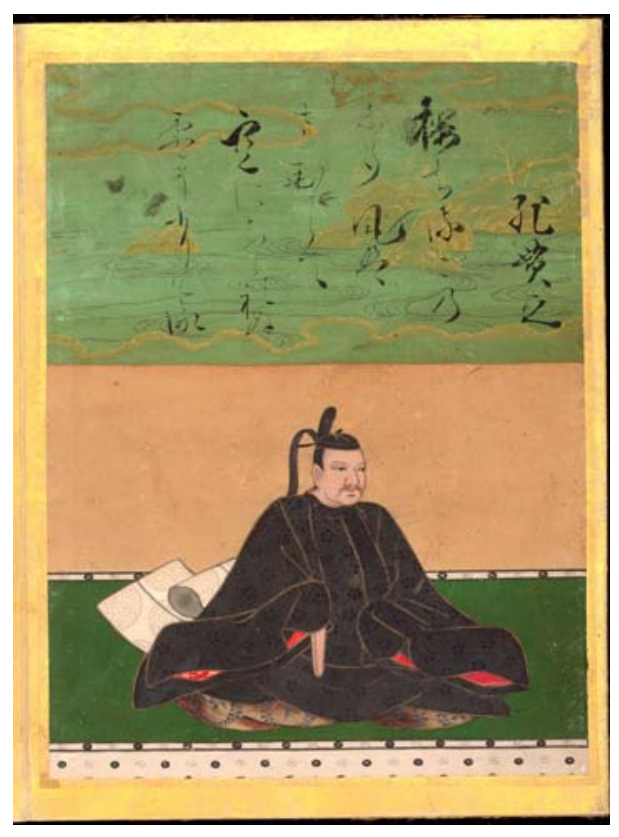

そのために、まず主要な歌仙絵での歌の異動 を一覧とする。ここでは、猪熊信男所蔵本 7 本 を含む『古筆切序説 下』のデータに、遠州本等 を補充した二十四本を用いることにする。個々 の解説は略す。データの形式は、上記の柿本人 麻呂の歌ならぼ、「ほのぼのと」を1、「龍田川」 を2、「梅の花」を 3 、「秋去れば」を 4 として、 各本での歌の種類を表とする。歌に若干の語句 の異動があっても、とりあえず同じ番号を振る こととする。各歌人についてこれを行えば、2 $4 \times 36$ の行列ができる。これはあたかも、各 本が 36 個の遺伝子を持っているかのごとくで あり、遺伝子の座が歌人ということになる。

もとより歌仙絵としては、絵の類似、左右を 別巻にするのか番を対比させて左一、右一の順 序に配列するのかといった様式の違いなど、 様々な要素があるが、ここでは和歌のみを考え る。そして、これを科学的解析の対象としてみ ようというのである。

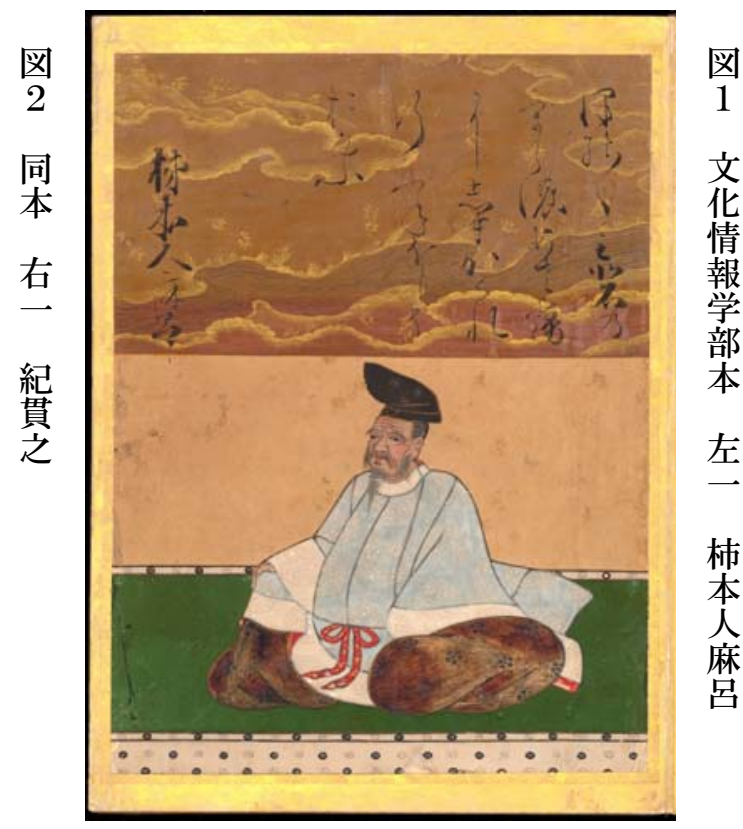




\section{3 NeighborNet, SplitsDecomposition}

ここで解析のための手法としては、“遺伝子” ということを踏まえれば、分子生物学で用いら れている方法が思い浮かぶ。但し、確率論的な 仮定は置きがたい。また、生物では起きないよ うな“混血”が頻繁に起こると思わねばならな い。即ち、本来別系統であるはずの 2 つの歌仙 絵を参照しながら、一つの歌仙絵を作ることが ありうる。もとより生物学でもこの系統の混雑 は考慮されているが、それよりも格段に激しい ことが起こる。従って、系統は tree（輪状のル ープ、つまりある点から一方向に進んで元の点 に戻る経路が無い）よりも網状の network で 見るのが望ましい。

このようなデータの系統解析では、通常最節 約 tree を求める。この場合 20 個の最節約 tree が求まる。それらから Supernetwork を構成 することもできるが、ここでは別の方法として、
NeighborNet 並びに SplitsDecomposition を 用いることとする。これらは親縁関係を表示す るのに適切であることが知られている。

NeighborNet の図 3 によれば、佐竹本と類縁 である道澄本・拾穂 2 本とともに文情本がある。 またその近くに、覚盛本・探幽本がある。そし て一方には北野本と類縁なものがまとまってお り、その他は大きく離れていることがわかる。 つまり、佐竹本、北野本は確かに基準的なもの と思われていたことが知られる。現在覚盛本の 実体は明らかでないが、それもまた古い形態で あったかもしれない。探幽本は狩野探幽の絵、 歌は照高院道晃の筆と極められていた屏風であ り近衛家旧蔵であったが、覚盛本との関係は明 らかでないのだが極めて良く似ている。

ここで特に大きくはずれた諸本を削除して、 さらに SplitsDecomposition によって詳細を みてみよう。すると、文情本の位置がさらに明

図 3 NeighborNet

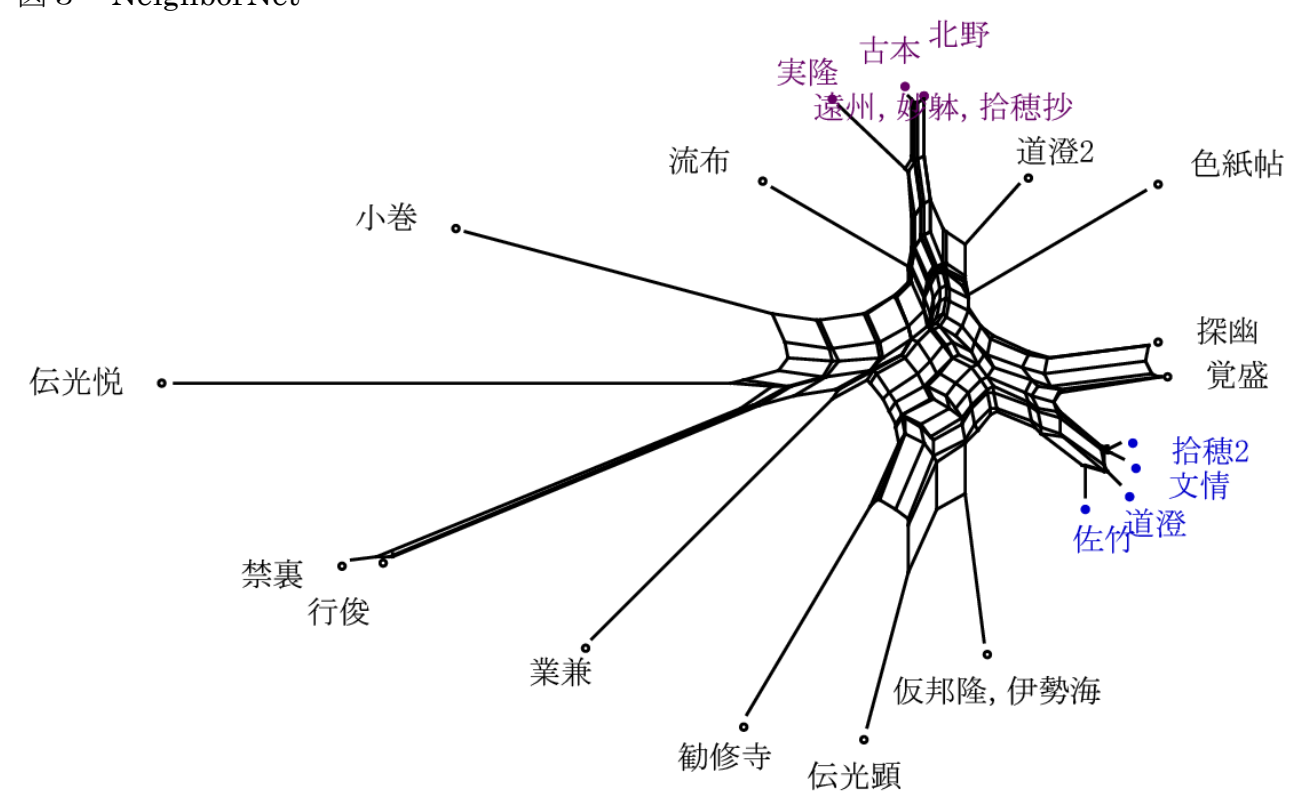


確になるであろう。

13 本からなる図 4 によれば、左に北野本と それからの派生、右に佐竹本と派生と見なせる ものの 2 群に分かれている。そして、文情本は 右の中央の点に近いところに位置している。こ れによれば、文情本に近いものが、右の群の原
型であったと見ることが可能である。

また、大きな平行四辺形から出ている伝光顕 本は、その左右の勧修寺本と伊勢海本の中間的 性格をもっており、両者が混じったものである とも、その両者の原型であるとも考えうる。尚 参考のため、Supernetwork を図 5 に掲げる。

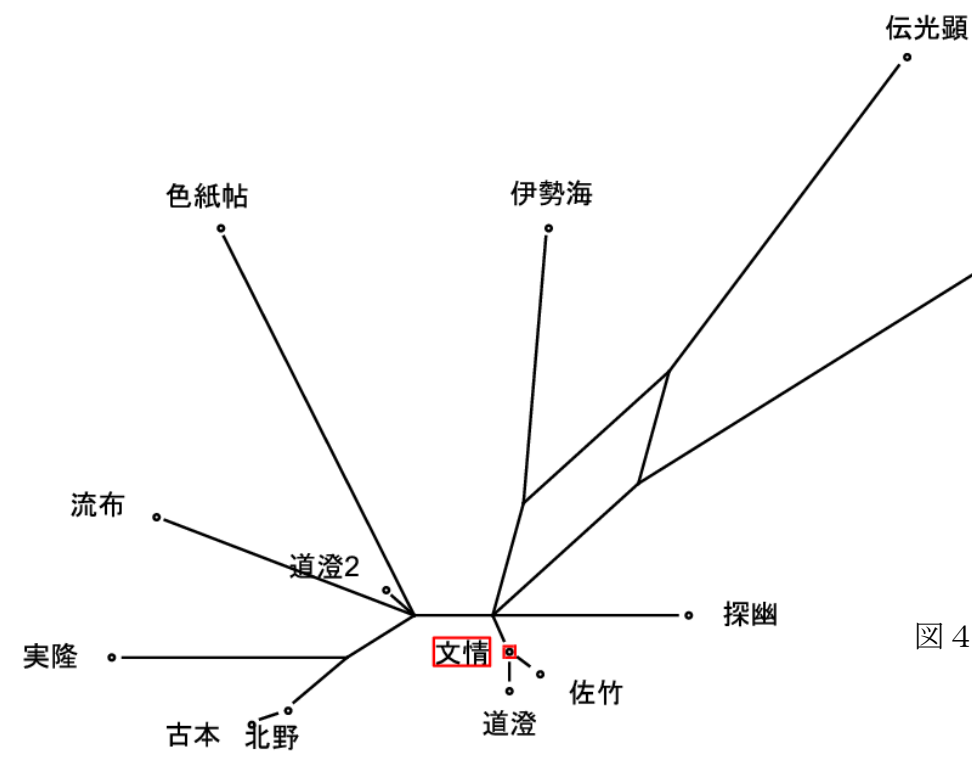

勧修寺

図 4 SplitsDecomposition
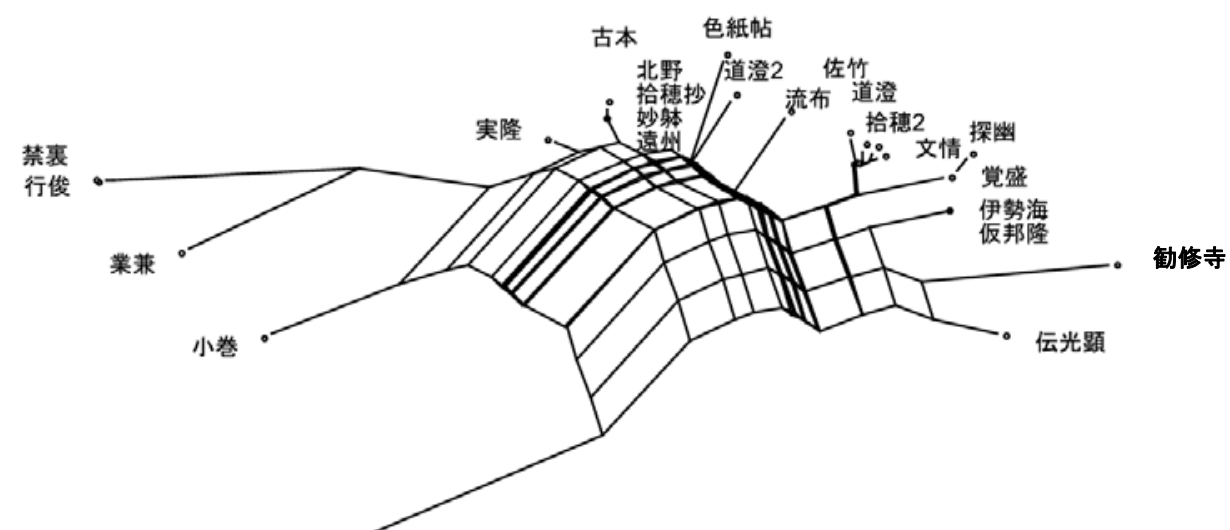

図 5 Supernetwork 


\section{2 歴史の復元}

\section{1 池坊専応口伝}

華道書として最も著名なものとして、池坊専 応口伝』がある。大永から天文に活躍した、京 都六角堂の僧侶、池坊専応の伝書であり、口伝 ではないが通称としてそう呼ばれる。特に川端 康成がノーベル賞授賞式においてこの冒頭の華 道理論の一節を引用したことでよく知られてい る。構成は、華道論、実技的内容、そして最後 に座敷飾の伝として、『君台観左右帳記』とよく 似た飾図を記載する座敷荘㛜之図がある。

この伝書には、奥書として伝授の相手と年月 日を明記しているものと、奥書の無いものがあ る。後者の中でも、天文十二年の行法記録にあ る専応の花押と同じ花押の記された、冒頭を欠 する伝書が、何時のものと考えうるかが問題で あった。座敷飾の部のみで判断を下寸必要があ る。以下この伝書を「花押」と略す。
また、杮葉文庫所蔵『立花並座敷飾』の末尾 にも、類似した座敷荘厳之図がある（以下「荘 厳」とする。さらに、彦根城博物館所蔵の弘治 三年九月に周永が相伝した伝書（以下「井伊」） も類似した内容を持つが、一次相伝の時期が明 らかでない。以上、花押・荘厳・井伊 (の原本) の 3 件の時期的な位置づけが問題である。

そこで、戝にかかれている様々な道具や飾り つけの異動、また飾りの条文での異動を考察し て、それを伝書の変遷の中に位置づけることが できるかを考察する。これは前章に比べて小規 模なものであるが、それだけに理解しやすい結 論を得ることができる。

\subsection{Supernetwork}

まず初期の伝書としては、大永三年本がある が、この奥書は必ずしも信用できない。しかし、 内容的には古いものと思われる。次に、享禄三

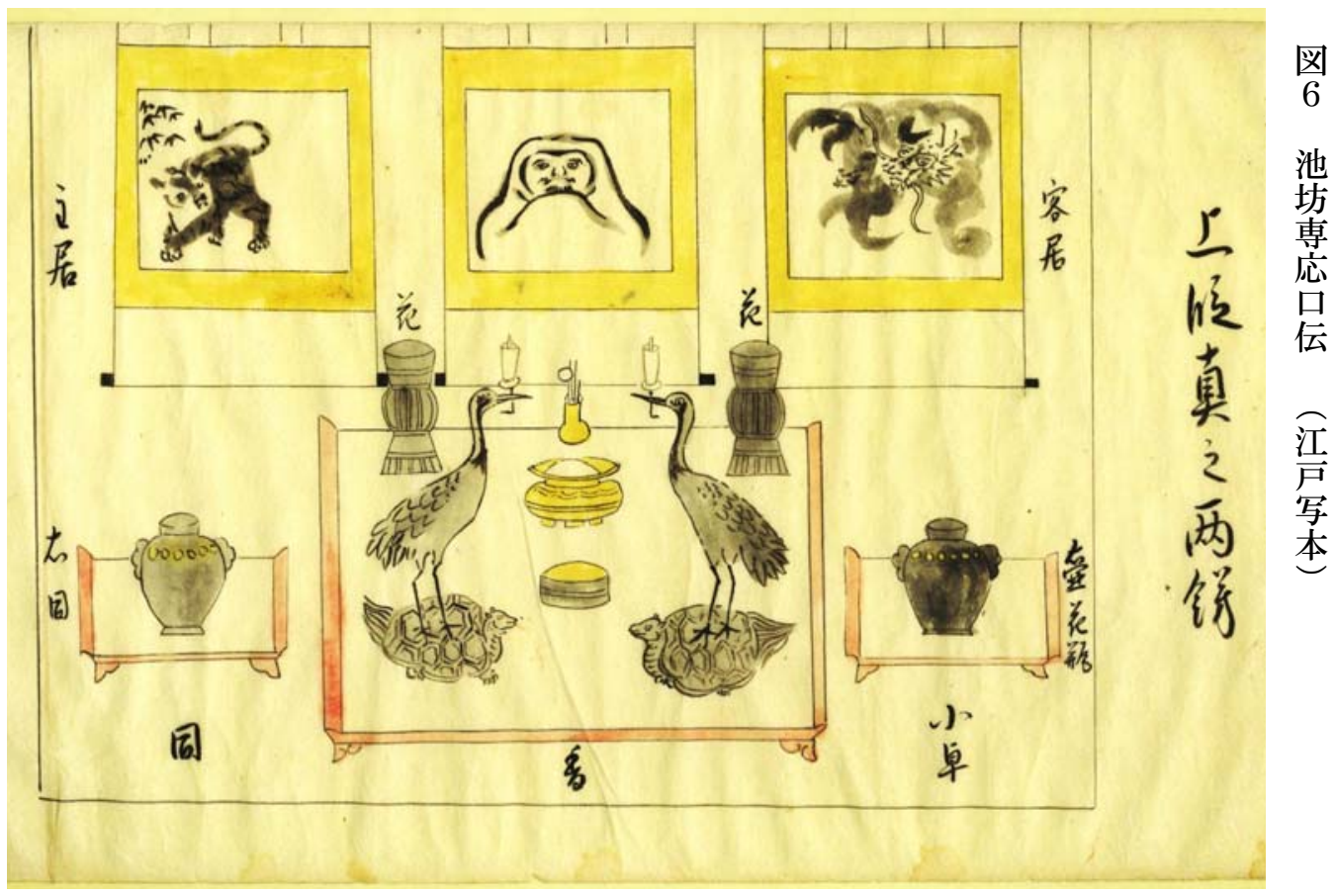


年本がある。また後期のものとしては、天文六 年、十年、十一年、専栄による十四年本があり、 条文の順序の相違をのぞけば、天文十年以降の 内容は同じである。それらが古活字本、群書類 従本の元となった。従って、天文十一、十四年 本は考察の対象としない。

本件の場合、8つの再節約 tree を合併した SuperNetwork は殆ど tree であり、3つの検 討を要する写本は、初期と後期との間に位置し ている。つまり中期に相応しいと、判断しう る。NeighborNet, SplitsDccomposition は、こ の場合類似した図になるが、若干情報の錯綜が あることがわかる。

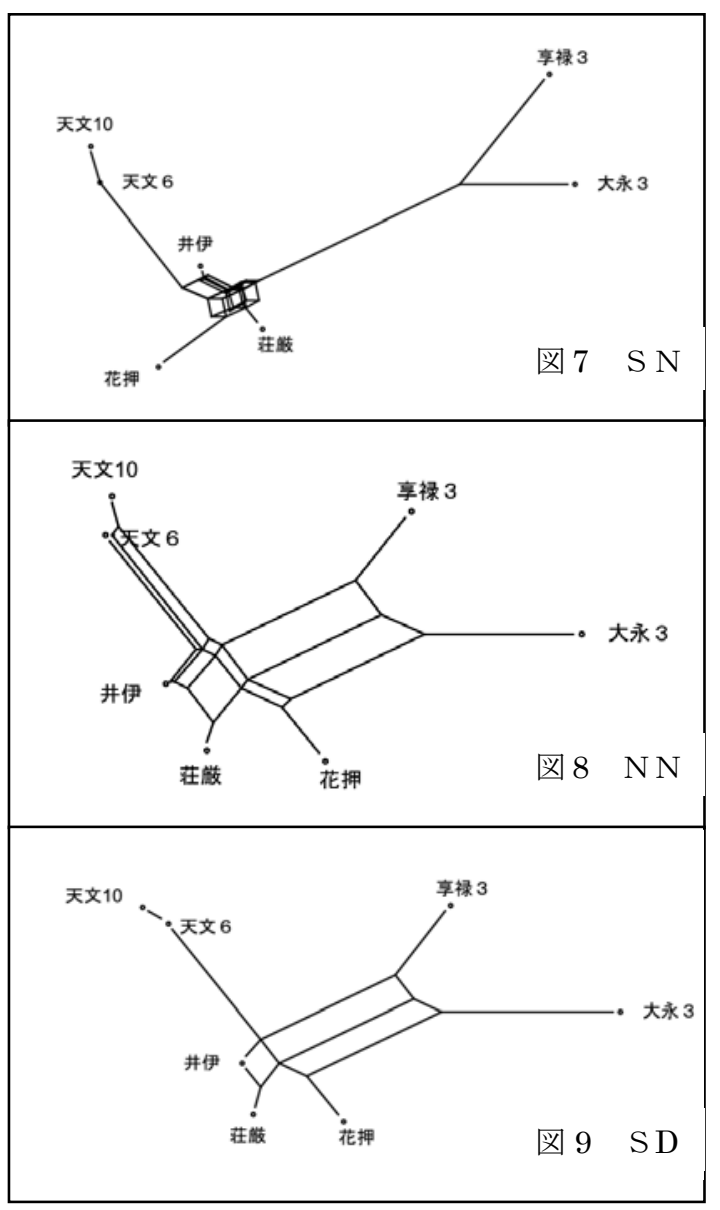

\section{3 茶入の形（なり）}

\section{1 茶入の見所}

鎌倉末期から茶や香の賞玩が広まり、室町時 代にはそれが茶の湯、香会として定着する。特 に抹茶を入れる小型の盇は、抹茶盇（すりちゃ つぼ）とよばれ、様々な形態が賞玩された。中 でも茄子（なすび）に似た小型の丸い茶入が最 高位の賞玩をうけていた。後には、肩衝（かた つき）とよばれる大型の茶入の地位があがり、 新田肩衝・初花肩衝がその一位・二位であった。 これらの茶入について、形 $($ なり)・比 (ころ)・ 土・薬・口作、といった鑑賞上の見所が、すで に天文年間には確立していた。この最初の $2 つ$ は、shape と size と表現できる。

そして、良い shape と適切な size、かつ土・ 薬による表面の景色が優れていると判断された ものが、名物茶入として喧伝された。これらは 大変微妙な鑑識眼によってなされている。そし て、名物茶入は「名物記」に時には図入りで記 載され、茶人の共通理解となっていた。

一体どのような茄子が好まれたのかを、形態 測定学的に考察してみよう。厳密には側面図が 必要であるが、ここでは『大正名器鑑』記載の 茄子の図から 14 件を選ぶ。

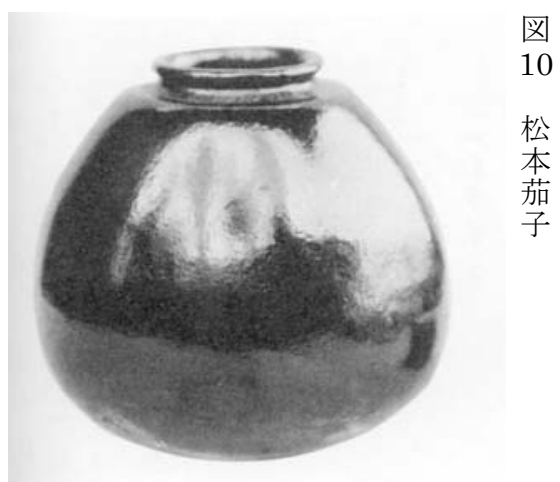




\section{2 Elliptic Fourier Descriptor}

形態の外郭線を記述する有効な方法として、 Fourier 級数を用いる楕円フーリエ記述子、 （EFD：Elliptic Fourier Descriptor）がある。外 郭線の $\mathrm{xy}$ 座標各々を Fourier 展開し、その第 一近似の楕円の長軸をX軸にとって標準化する のが通常である。これを茄子に適用する場合は、 円形に近いため、主軸の取り方を若干変更する 必要がある。ここでは、口の中央が X 軸に乗る ように調整した。

その 14 個の Fourier 係数を 20 項まで算 出し、主成分分析によって第二主成分までで散 布図を作れば、図 11 のようになる。

かつて特に形（なり）が良いとされていたの は富士茄子であった。そのあたりに著名な京極 茄子、いずれも紹鴎の好みと伝える、澪漂茄子・ 玄哉茄子などがある。
古来著名であったつくも茄子は、かつて豊臣 家が大坂城で滅びたときに火中し、それが修理 された時に口が高くなってしまったため、かな りはずれたところにいる。また、松本茄子も修 理を経ているが、よく似ているとされた種子島 茄子と確かに近接している。宗伍茄子が近くに あるが、第三主成分で分離する。

茜屋茄子・曙茄子などは、天正期にはそれほ ど評価されていなかったが、それらが外れてい ることがわかる。

この主成分を Fourier 係数に還元すれば、主 成分方向での形態の変化が説明される。第一主 成分が増加するといわゆる尻膨の形態に移行す る。第二主成分は本体の上部が細めになる。

このようにして、古人の審美眼をデータサイ エンスとして解析することもまた可能となって いる。

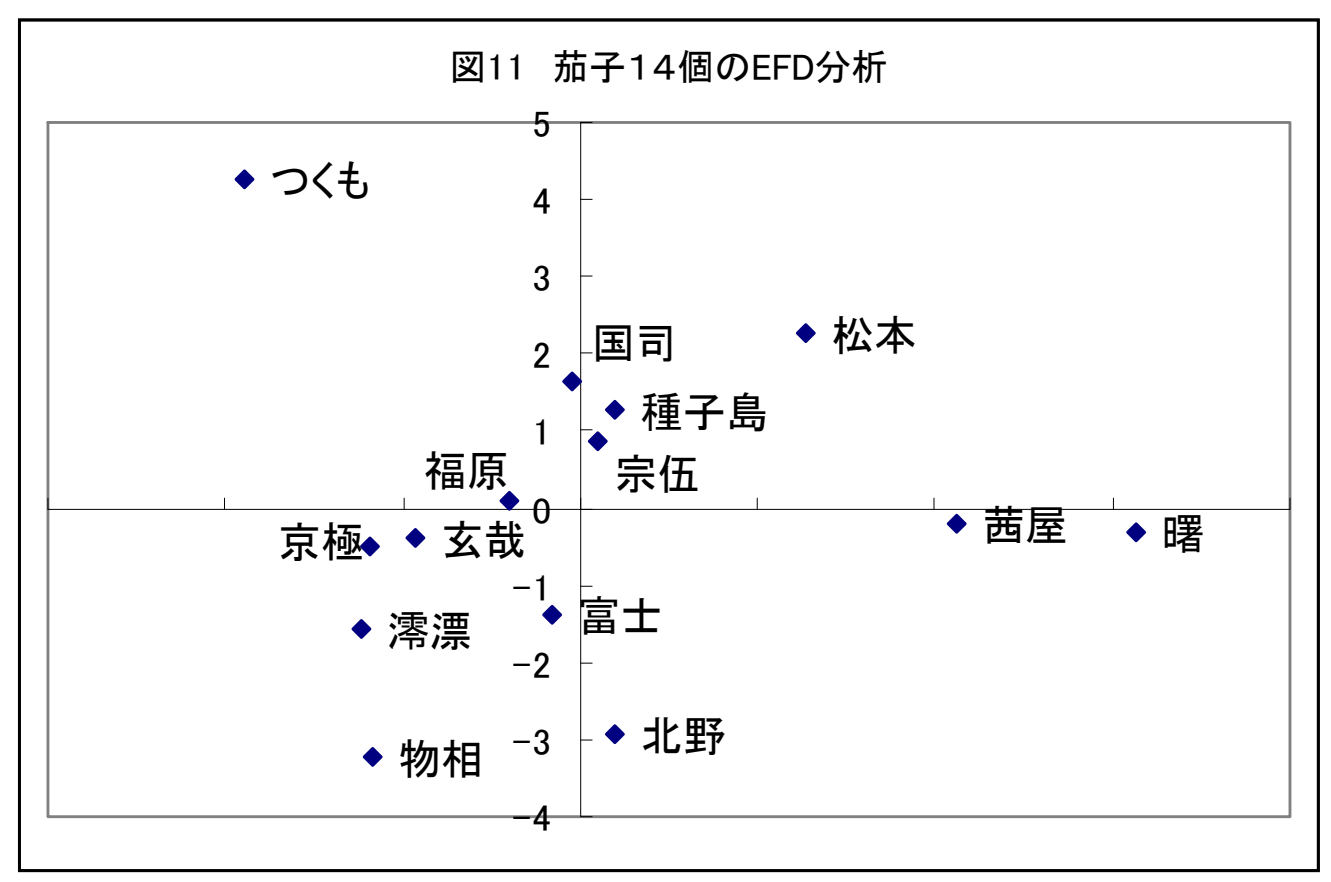




\section{4 まとめ}

第一章「歌仙絵の系譜」では、歌仙絵の重要 な要素である記載和歌の種別を見ることによっ て、大きく「佐竹系」と「北野系」とでもよぶ べき系統が認められ、それらから他が派生して いったという、歌仙絵の生命誌が読み取れた。 特に、同志社大学文化情報学部所蔵本は、佐竹 本に近く、かつある種の原型に近いのではない かという想定がなされた。

第二章「歴史の復元」では、成立年代不明の 写本に対して、そこに記載される文言、図、図 の添書の異動まで含めてみることによって、『池 坊専応口伝』が、初期一中期一後期という歴史 的経過、つまりは生命誌を辿り、安定状態に落 ち着いたということが見やすく説明できた。

これらに用いた手法は、SD, NN, SN (Splits Decomposition, NeighborNet,SupreNetwork) などであり、元々は生物学において系統をみる ことで使われていたものであった（実際のプロ グラムは PAUP*と SplitsTree を使用)。今後 は、文献あるいは文化事象に適するプログラム の開発も必要となると思われ、実際進行中のこ ともある。またこれらの手法は、古典籍の校合 データを元にして系統をみることに適用されて おり、その㜴矢はカンタベリー物語の写本系譜 にSD 画使われたことであった。現在では、源 氏物語にも部分的に適用され、また古今六帖の 分析には他の手法も援用されている。

必ずしも機械的に処理できるとは言えない面 もあるが、染意的な判断ではなく、データを提 示して説明できることから、説得力のある議論 となるのが大きな利点である。
第三章「茶入の形」では、茶入の形態評価の 手法として、Morophometrics（形態測定学） における数学的手法としての楕円フーリエ記述 子を用いた。実際のプログラムは、岩田洋佳氏 （(独）農業・食品産業技術総合研究機構）の開 発された shape を用いている。これもまた、 生物学において種子や果実の形態分析に通常使 われるものである。

この手法はもとより茄子に限るものではなく、 茶入の肩衝でも可能であり、のみならず輪郭に 重要な要素のある場合の美術品や絵画などにも 適用可能である。

以上の手法の特徵としては、いずれも数学的 な深い理論に根ざしているということであろう。 統計的手法はもとより重要であるが、それ以上 に数学的理論の上に立った応用が現在多く使わ れるようになっているという一端を示した。

\section{参考文献}

[1] SplitsTree, http://www.splitstree.org/

[2] PAUP*, http://paup.csit.fsu.edu/

[3] Shape, http://cse.naro.affrc.go.jp/iwatah/

[4] 京都美術青年会 会誌十六号「古筆切序説 下」、 1938.

[5] 高橋義雄編：『大正名器鑑』、審美書院 1925.（ア テネ書房再版 1997)

[6] 矢野環：『君台観左右帳記の総合研究一茶華香の 原点、江戸初期柳営御物の決定一』、勉誠出版 1999. [7] 矢野環：「名物記の生命誌」、茶の湯同好会『茶の 湯』連載 2004.10-2006.12.

[8] 矢野環：「名物茶入の物語」、淡交社『なごみ』連 載 2007.1-2008.6. 